\title{
Collaboration, Technology and the Science of Learning: Teaching Cognitive Science to Undergraduates
}

\author{
Naomi MIYAKE \\ (School of Computer and Cognitive Sciences, Chukyo University)
}

Our research on principles for designing effective learning environments is based on recent research on how people learn and on the following: (1) knowledge has to be constructed by the students themselves, (2) constructive interaction deepens conceptual understanding, and (3) such collaborative construction itself has to be maintained by cultural practices. The present article reports on 2 curriculumtechnology combinations: one for helping advanced students learn how to construct their own knowledge collaboratively, and the other for guiding beginning students, who may still be embedded in a more typical lecture style, to start seeing the power of intellectual collaboration. The former was supported by an enhanced note-sharing system, Reflective Collaboration Notes, or ReCoNote, with an emphasis on the function of this system for making relations. The latter utilized a bulletin board system that could be annotated. Interactive Query Raiser was prepared to facilitate sharing academic interactions among peers and experts. In the 3 years we have done this, college students have shown high flexibility in learning and creating both their knowledge in cognitive science and new ways to use their technological environment. When the course work is carefully designed and practiced, students gradually come to show respect for the community norm of constructive interaction.

Key Words : collaboration, technology, learning sciences, introductory cognitive science, college education, college students

"Designing effective learning environments includes considering the goals for learning and goals for students. This comparison highlights the fact that there are various means for approaching goals of learning, and furthermore, that goals for students change over time. As goals and objectives have changed, so has the research based on effective learning and the tools that students use. Student populations have also shifted over the years. Given these many changes in student populations, tools of technology, and society's requirements, different curricula have emerged along with needs for new pedagogical approaches that are more child-centered and more culturally sensitive, all with the objectives of promoting effective learning and adaptation (transfer)."

(Bransford et al., 2000, How People Learn, Expanded edition, p.246)

\section{I . INTRODUCTION}

We may be witnessing the birth of some new science of learning. Papers are written on new types of collaborative learning research, small but solid conferences are emerging, and big projects are yielding promising results. They are mostly done in collaborative fashion with researchers, practitioners, curriculum and supporting technology designers, and administrators, sometimes even with other community members like parents and field experts, all working together. Some causes for this new development include 1) deepened understanding of how people learn (e.g., Bransford et al., 2000), 2) accumulation of research findings on situated and collaborative cognitive processes (e.g., Brown, Collins \& Duguid, 1989; Bereiter \& Scardamalia, 1993; Fishman \& O'Connor-Divelbiss, 2000), and 3) growth of practical knowledge of how technology can help support the collaboration for learning (e.g., Communications of the ACM, 1993; Cognition and Technology Group at Vanderbilt, 1997; Linn \& Hsi, 2000). In this article, I report some of our endeavors in expanding our fundamental cognitive research understanding into practi- 
cal learning experiments.

Teaching cognitive science to undergraduates is a challenging task because the field is highly interdisciplinary, and many new concepts and approaches must be introduced in a relatively short period. It is desirable that the students be exposed to the diversity of approaches to human studies and their interplay from the beginning of their study. Collaborative learning situations are particularly suitable because they present the challenges that researchers in the field undertake regularly as professionals. However, this requires careful design of the curriculum, and methods to accomplish this have not been widely investigated. In order to meet this challenge, we are developing a relatively complex curriculum where the structure of the course itself could guide the students' activities.

A successful collaborative curriculum is often a combination of well thought-out course work and a set of relatively simple but well designed tools. To take fuller advantage of this combination, such curricula themselves have to be organized into a larger course sequence, so that the students can build upon what they take out of one collaborative course into other, more advanced ones, leading them to be designers of their own life-long learning. This paper is a progress report on such a collaborative course-sequence organization being developed at our department for teaching cognitive science to undergraduates. We focus on two curriculum-technology combinations, one for helping advanced students learn how to construct their own knowledge collaboratively, and the other for guiding beginning students, who may still be embedded in a more typical lecture style, to start seeing the power of intellectual collaboration. The former is supported by an enhanced note-sharing system with an emphasis on its relation-making function, while the latter utilizes a bulletin board system that could be annotated which was prepared to facilitate sharing academic interactions among peers and experts. Analyses of the log data and the outcomes so far suggest that for each course there was a considerable amount of academic as well as social learning, with implications for how these two could then be organized into a larger course sequence.

\section{COURSE DESIGN PRINCIPLES}

When we design a collaborative learning situation, we take three standpoints from recent advances of cognitive studies on learning (cf. Bransford et al., 2000). They are:

- knowledge has to be constructed by the students themselves,

- constructive interaction deepens conceptual understanding, and

- such collaborative construction itself has to be maintained by cultural practices.

We first elaborate a little on these points, and then go on to report the tools and curricula we use, with some results of our studies in the following sections.

\section{Active knowledge construction by students}

Despite many studies showing the potential value of structured knowledge in learning (Chi, 2000; Williams, Hollan, \& Stevens, 1990; Lave, 1988), the notion is not actively put in use daily in college courses. In knowledge construction, there are two levels of understanding, or knowledge structuring. One is global, a higher level structure that allows students to write a summary report, and to understand the whole structure of the materials covered in the course. The other is a smaller scale structuring, for building blocks for topics covered in each class. Understanding some independent research piece may be a typical example for an educational psychology class. In traditional, lecture-centered classes, students are expected to learn such pieces by following the explanation laid out by the teacher, but are not always given chances to engage actively in overt knowledge construction on either of these levels.

Methods like the jigsaw classroom (Aronson \& Patnoe, 1997) appear to have a better potential for renovating this situation. The jigsaw method was first developed by Aronson to cope with cultural diversity in classrooms. The method was then expanded into a more sophisticated system to turn such culturally diverse situations into learning resources (some current reports can be found at http://www.jigsaw.org/). In an ordinary jigsaw class, students first study a piece of material in an "expert group," and then form a separate study group, 
or "jigsaw" group, consisting of one member from each of several "expert" groups. This method has been carefully tested for its effects on a diverse set of topics including children's acceptance of their groupmates as intellectual peers, their self-esteem, and their mastery of the classroom materials. According to Aronson and his colleagues, the effects are consistently positive (for references, see above web site).

The jigsaw method can create a rich environment for intellectual collaboration and has been used by other researchers in the field of collaborative learning (e.g., Brown, 1997). So far, it has been mainly used for facilitating smaller-scale, knowledge piece construction. We also see a high possibility in expanding this into a practice of helping students structure the material of the entire course, on a more global level. We propose a way to achieve this goal, both by arranging the classroom activities differently and by providing a note-sharing system with special emphasis on relation-making for broader knowledge construction than is regularly seen in collaborative classrooms.

\section{Collaborative knowledge construction}

Our curriculum design is based on our theoretical understanding of constructive interaction (Miyake, 1986; Shirouzu, Miyake \& Masukawa, 1999, 2001). The joint effort promotes each participant's own understanding, because the participant's thoughts have to be made much more explicit than in solo thinking, which in turn gives the participant more chances for reflection. Also the participant's solving processes being shared more extensively is the key for the superiority of pairs over solos (Miyake, 1994; Miyake, 1996). This means that the students should also be given tools to make their progress visible to themselves as well as capable of being shared with others, so that all the members can take advantage of sharing the externalized thoughts.

For smaller levels of construction, dividing the survey task into sub-themes and having the students share the results can serve to create constructively interactive situations. The jigsaw is an excellent method for this purpose, and some simple note-sharing technology can support this. In comparison, for higher-level knowledge construction, it is beneficial for each group to realize that similar "deep" under- standing is also taking place in groups other than their own, which they should also take advantage of. In order to help the learners benefit from the whole class, the course work has to be designed to encourage such wider-range relation-making explicitly. This relation-making process itself needs to be made visible and capable of being shared. We try to achieve this by enhancing a regular note-sharing system with a mutual-linking capability which we will describe in more detail later.

In section III, we report on a structured curriculum covering a single topic in cognitive science. In section IV, we will introduce a more complex curriculum, designed to present a broader view of the field to the students. By building upon the "jigsaw" method, we create a college-level work-oriented collaborative situation where students move in and out of hierarchically structured study groups to enable them to perceive the width and complexity of an interdisciplinary field such as cognitive science.

\section{Building an intellectually collaborative culture}

Constructive interaction is a rigorous task where each participant's thoughts have to be made explicit and available for scrutiny for others. It is highly motivating for those who seek deeper understanding, or for everyone desperately serious to reach such depth, but in general it does not come easily where there is little cultural support. College classrooms are, unfortunately, not always the place where intellectual collaboration is the norm. Some students may know that visiting a teacher after class and having some direct discussion is fun and beneficial, but they do not necessarily convey to others what they learn this way. Some may enjoy having intellectual conversation among themselves, but this tends to occur only among small groups of fixed members. Yet others may raise a question during class, but this gets lost quite quickly as the planned course of the lecture develops, putting question-answering aside. All of these are a seed for building an intellectually collaborative culture, and a technology to keep traces of such events for later viewing and shared reflection can serve as its foundation.

Based on this assumption, we developed a bulletin 
board that could be annotated in order to solicit and collect records of spontaneous interactions of question-answering and commenting and responding on lecture notes provided by the teachers. The collection is expected to grow, to represent a gradual expansion of the community which values the constructive type of interactions. Toward the end of this paper, we will report on how this system is embedded in an introductory course and provide some data.

\section{TECHNOLOGICAL SUPPORT FOR COLLABOR- ATIVE KNOWLEDGE BUILDING}

\section{Reflective Collaboration Notes: The system}

A collaborative learning support system called ReCoNote, or Reflective Collaboration Notes, has been developed and put in use in college-level cognitive science classes (Masukawa, 1999; Miyake \& Masukawa, 2000). It is a note-sharing system with a mutual-linking capability. When learners encounter two "linkable" pieces of information, they are explicitly asked to link them together with specific comments regarding the relationship. The linked comments are stored and presented in a list whenever the attached notes are viewed. The two pieces may be the student's own note, another's note, a group's note, or class material provided by the teacher. The system's mutual linking feature requires the learners to adopt multiple perspectives on the learning materials by asking them to write link comments bi-directionally, for example, for notes A and B, first from A to B and then from $\mathrm{B}$ to $\mathrm{A}$.

ReCoNote has two windows that show two sections of learning materials at once (FIgURE 1). The materials include the student's individual notes as well as group notes and teacher-provided learning materials with announcements of classroom activities and system support. Each note comes with a "link list," a list of comments with the authors' names for links that tie the information in the adjacent window to some other piece of information in the overall note system. Clicking on the comment causes the linked information to appear in the other window on the screen. All of the information can also be called up onto one of the windows by going through a menu provided at the top of each note.

To write a note, the student clicks on the "make a note" button, which opens up a new window. There is a separate small window where the title of the note can be written; this title will appear on the menu in a list of titles. If students wish to create a link between the two notes they are currently working on (most typically this happens when students are writing their own notes while examining another piece of informa-

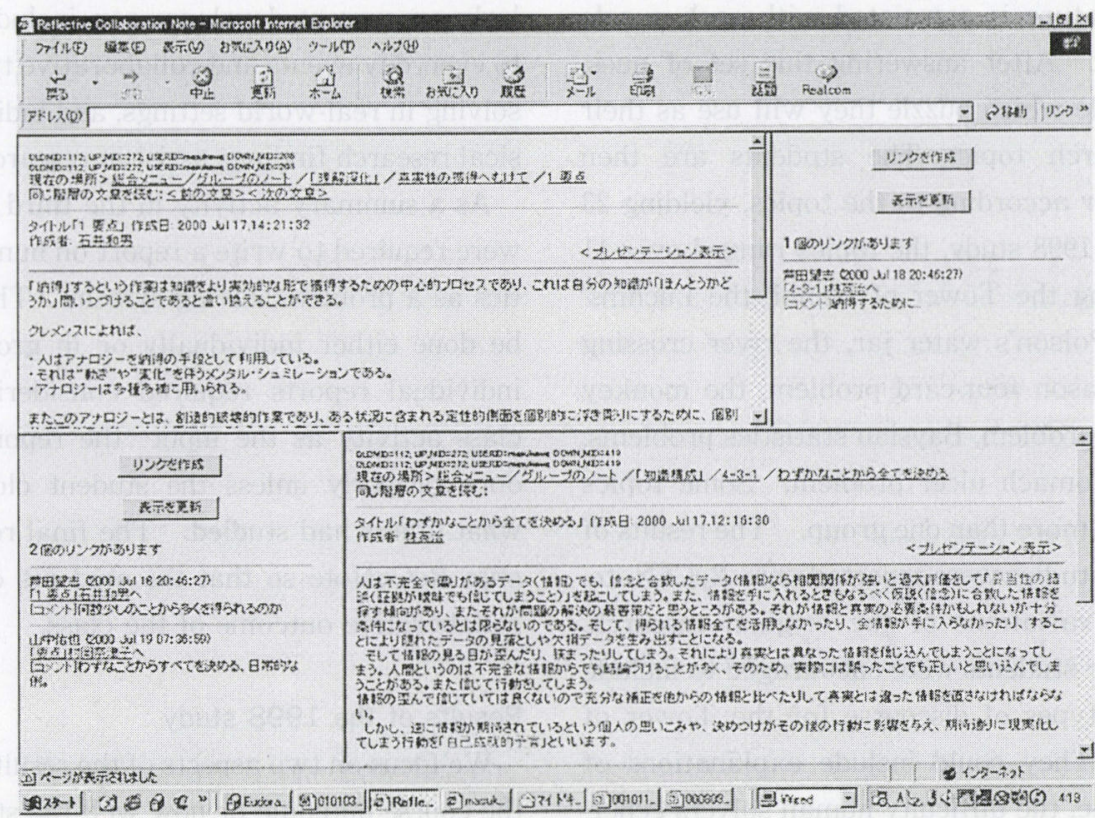

Figure 1 ReCoNote windows 
tion in the other window, such as teacher-provided learning material or notes created by other students), a click on "make a new link" at the bottom opens a new window with two slots in which to write comments to explain why the two pieces of information are related. There are two slots because the system explicitly asks students to think about the directionality of the link; with notes $\mathrm{A}$ and $\mathrm{B}$, one relation could be made from $A$ to $B$, while the relationship from $B$ to $A$ often requires another type of specification.

\section{The course activities}

Several curricula have been developed to take advantage of ReCoNote, covering both upper and lower level undergraduate courses in cognitive science. First we report on a course on problem solving, an upper level elective course. The goal of the course is to review the literature and write a summary report on human characteristics as a problem solving system. This took place in 1998.

There were three phases in the class. In the first phase, literature review, students were grouped into small "expert groups" according to their interest in topics covered in classical problem-solving literature. In the first class, they answered questions about classical puzzles-what they are, how to solve them, and how much literature is associated with each puzzle that they know. After answering this set of questions, they decide which puzzle they will use as their literature research topic. The students are then grouped together according to the topics, yielding 23 groups. In our 1998 study, the topics ranged over 11 puzzles, including the Tower of Hanoi, the Luchins' water jar, the Polson's water jar, the river crossing problem, the Wason four-card problem, the monkey and the banana problem, Baysian statistics problems, and Dunker's stomach ulcer problem. Some topics were covered by more than one group. The results of these literature studies were reported onto ReCoNote, covering some variations of the original research. For example, the students were encouraged to include many different types of discourse for the Tower of Hanoi puzzle. They could include explanations of the original game, the difficulty human solvers generally encounter when solving its typical dissemination (five-disk version), the recursive structure of its general solution, its role in the development of the typical information processing model of problem solving system, like GPS in the original Simon and Newell formulation, its variations, like the adaptive production systems, and Zhang and Norman's re-formulation of its dependence on external resources.

The second phase was devoted to relation-making, utilizing ReCoNote's mutual linking function. After three weeks of preparation, each group reported what they had reviewed to the class. During this presentation, the "audience" students were encouraged to consider how they would relate what was being presented to what they had researched under their title. They were then required to link the important relations among the notes on the system.

The groups were then asked to report to the class on the linkages they had made from among all the class notes. Prior to this, the teacher gave a short instructional lecture on how the pieces could be tied together, actually pointing to possible clustering features like the historical roles the puzzles played and the human characteristics each puzzle reveals. The linking and the presentation of the linkage by the students took another three weeks. After the presentations, the teacher gave a rather detailed one-hour lecture providing an overview of the research field, focusing particularly on current developments, including application to everyday events and collaborative types of problem solving in real-world settings, and indicated how classical research findings assist in research development.

As a summary activity in the third phase, students were required to write a report on human characteristics as a problem-solving system. This report could be done either individually or in groups. Even the individual reports required considering the overall class activity as the input-the report could not be done properly unless the student closely examined what others had studied. The final reports were put onto ReCoNote so that the students could share the collaborative outcome of the class.

\section{Results of the 1998 study}

We focus on two aspects of the results have. One is the course outcome or how well the students learned. This is analysed in terms of the quality of their term 
papers. The other is the students' activities during the class analysed by their log data.

\section{Course outcome: Students' concluding reports}

Forty per cent of the groups (10 out of 23) turned in high quality reports under the title of "Human Characteristics as Problem Solving Systems." This rate is fairly high compared to other years, if we consider the demand for quality of the reports. We identified three types of reports from among those received: Integrated (3 groups), Listed (4), and Self-Centered (3). In integrated reports, the students covered all the materials studied by the class and attempted to provide an integrated view of a human being as a problem solver. They furnished specific characteristics uncovered by different pieces of research and then tried to depict a holistic view. Listed reports, in contrast, literally listed all the studies contributed by the class members. These were exhaustive and meticulous reports, reflecting the hard work done by the students, though less effort had been made to integrate them. The Self-Centered reports never ventured very far from the original topic each author had begun with in the class, yet there were clear traces of their efforts to integrate the information provided by others. The difference between this and the other two types was primarily that the students who generated this type were more selective. They tended to pick out only the studies that were relevant to their topic of research and structured the reports around those studies.

\section{Course activities: Establishing relations}

The activity levels observed during the classes were also higher in the 1998 class. Overall, fifty-seven students used the notes, with a total of 749 log-ins, and they all successfully finished the course. They created 310 notes in total, among which 114 were by individuals and 196 were group notes. One hundred eightynine links were made to them by 32 students. Table 1 shows how many notes were actually visited and by whom.

As shown in TABLE 1, the students visited other group's notes often. Among 23 groups, six groups visited notes written by all the groups and the other 14 groups visited notes from more than 13 groups, in- dicating that the notes were used actively during the course, regardless of who made them.

A comparison of the types of notes made either by an individual or by a group with when they were made (in which phase of the class) indicated that groups wrote notes in the literature study phase, which reflects the initial collaborative efforts that were made by the students. In contrast, the students worked more individually toward the end of the course, when they spent more time writing summary reports by tying the relevant notes together.

All of the links (189 in total) were similarly categorized according to the types of notes they linked, i.e., whether they linked notes within one's group (own group), notes from other groups who studied the same topic (same topic/other group), or notes by other groups on different topics (different topic). Three notes were unclassifiable. See TABLE 2. As the course developed, links spread from within one's own group's notes to cover notes created by other members associated with different study topics. This suggests that the students were engaged in relation-making activities, with notes provided by other members of the class serving as building blocks to re-structure the field of problem solving research from each student's own perspective.

Among the 189 links, 133 had comments in both directions, while 43 offered one-directional comments only. The comments were used mainly to explain the characteristics of the linked notes and their relationships. The comments were occasionally too long to fit as a "comment" to the link (i.e., longer than would fit in the given slot), in which case a whole new note

TABLE 1 Total number of notes visited by one's own group and other groups

\begin{tabular}{c|c|c|c}
\hline Own groups & Others' groups & Cannot tell & Total \\
\hline 383 & 6,924 & 491 & 7,798 \\
\hline
\end{tabular}

TABLE 2 Number of links made -1998 class

\begin{tabular}{l|cccc}
\hline & $\begin{array}{c}\text { Litera- } \\
\text { ture } \\
\text { study }\end{array}$ & $\begin{array}{c}\text { Relation } \\
\text { making }\end{array}$ & $\begin{array}{c}\text { Summary } \\
\text { writing }\end{array}$ & Total \\
\hline Within own group & 22 & 15 & 31 & 68 \\
Same topic/Other group & 6 & 6 & 5 & 17 \\
Different topic & 1 & 49 & 51 & 101 \\
Unclassifiable & 1 & 0 & 2 & 3 \\
\hline Total & 30 & 70 & 89 & 189 \\
\hline
\end{tabular}


was created to provide enough writing space for the commentary, and these comment-notes were then linked together. FIGURE 2 shows where the comments were written: on notes and links, on linked notes, on links only, or other. Toward the latter part of the course, students started to use more notes for comments. One possible explanation for this phenomenon could simply be that they had more to express.

FIGURE 3 depicts the relationship between the types of final reports and the number of notes visited by the groups. The groups that produced the listed and integrated types of reports had a greater tendency to visit the created notes, particularly in the relationmaking and summary-writing phases. These activity patterns match the content and the quality of the reports, indicating that the activities ReCoNote was able to solicit had positive effects on the students' performance.

\section{RECONOTE ON A MORE COMPLEX DESIGN}

In the summer of 2000 , ReCoNote was used in a course on the "Cognitive Science of Learning and Development." This was a three-day concentrated elective course for third and fourth year students.

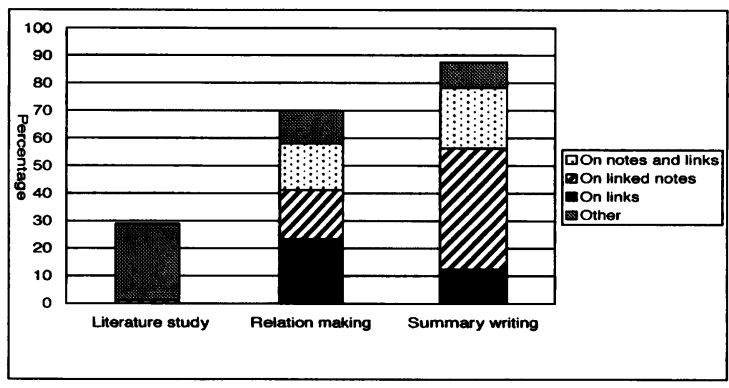

Figure 2 Where the comments were written

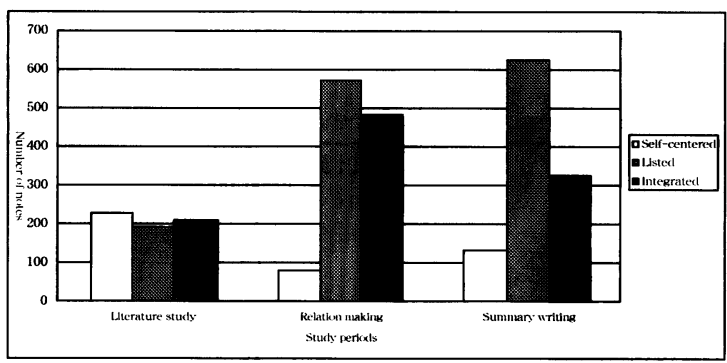

FIGURE 3 Number of notes visited during each study period for each report type
The ultimate goal of the class activities was to propose a new design for a traditional college course, based on their understanding of how people learn and generate knowledge. The teacher prepared twelve pieces of influential work done in cognitive science, taking three pieces from each of four different larger topic areas. The four areas were :

--The everyday and situated nature of knowledge use and knowledge formation ("situated view")

--The constructionist approach to developmental studies ("developmental")

--The constructionist approach to knowledge use ("thinking and problem solving")

--The collaborative and socially distributed nature of cognition ("collaborative")

The teacher's intent for the final proposal was to have the experts from each of these four approaches collaborate to develop a proposal. In a sense, this formulation follows the jigsaw structure, but it also expands it. Students were encouraged to find relations among the contents of their own assigned piece, among pieces in the same approach, and then among studies done under the different approaches, by taking advantage of the mutual linking capability of ReCoNote.

\section{The course activities}

FIGURE 4 shows the structure of this complex jigsaw. Groups of three students were assigned to one of the twelve pieces of work prepared by the teacher, taking into account their interests as shown in their answers to the initial questionnaire. More than one group was assigned to a single research piece, to accommodate the class size. Thus student S11 in FIGURE 4 reads Piece 1 of the "Situated" approach, while T31 reads Piece 3 of the "thinking" perspective. The process started very much like the traditional jigsaw classroom: in the beginning, each student (e.g., S11) assigned to one-third of the original paper read it and prepared a summary in an expert group (e.g., S11+ S11'...to become expert on that part). In the jigsaw group that followed, three students who each read different parts gathered to co-construct the coherent whole of the original paper (e.g., S21+S22+S23 to cover Piece 2 in the "situated" approach). This was covered in the first day, in three 90 -minute classes. 


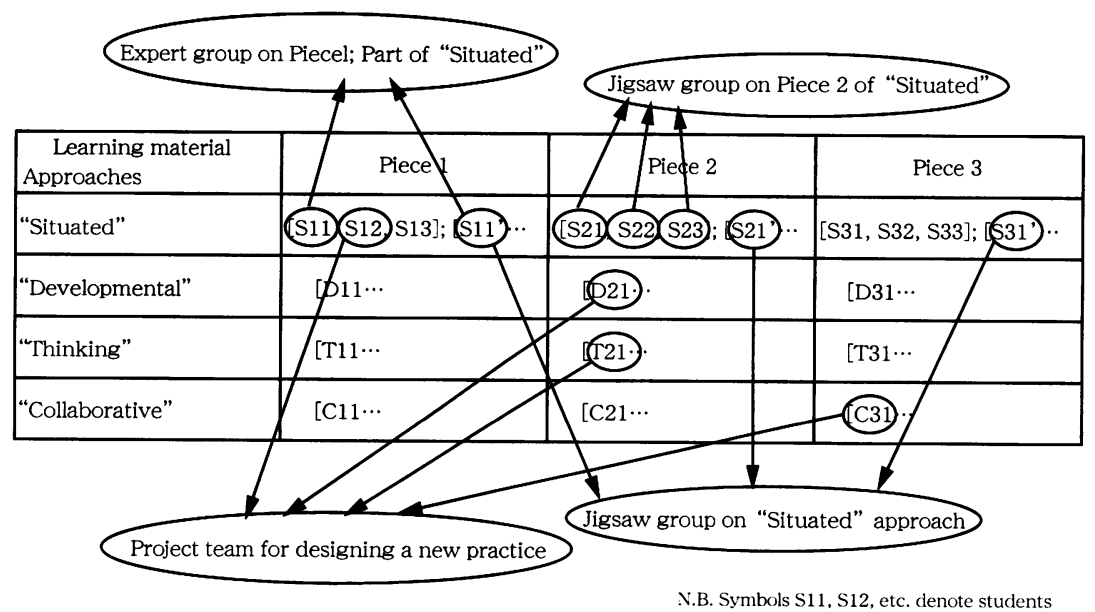

Figure 4 The complex jigsaw course work design for the 2000 study

The students worked on ReCoNote after the classes, writing up the day's work in preparation for their presentations the next day.

On the second day, three students from each paper group separated and independently formed new jigsaw groups, which then consisted of three representatives from each of the three different material pieces under the same approach (e.g., S11+S21+S31). Each member presented her summary of one of the three papers, so that at the end of this session all three were familiar with different kinds of work done under the particular approach. Again, there were in fact more than one set of such groups in each approach. Note taking on ReCoNote was encouraged during this phase, using the classroom notebook computers. The class convened at this phase and each group presented its version of what each particular approach is and how it should guide the design of new learning systems/ practices. There were overlaps because multiple groups presented based on the same approach. This overlap made it clear to the entire class that there could be different understandings of the same approach, opening up the possibilities for flexible applications of the approaches to their design task. After these presentations, "collaborative work teams" were created by selecting one student from each approach to design and propose a new learning practice (e.g., S11+D21+T21+C31). We had seventeen such groups (two had only three members), each of which was asked to work together to formulate a proposal. Answers to the initial questionnaire were taken into account for this grouping, so that students who had stated similar opinions regarding what to teach and how to teach it were grouped together.

Students spent the morning and the early part of the afternoon of the third day designing a new learning practice and preparing its presentation. Note-taking on ReCoNote on classroom notebook computers was again encouraged during this phase. At the end of the course, in the latter part of the third day, all the proposals were presented to the class in a poster session. The students were split into two groups; one half presented their posters, while the other half could meet with the presenters and engage in discussions with them. The halves switched roles in two 45-min sessions. The assigned paper reporting the proposal was due at the end of the course in three weeks, with refinements that reflected the questions and comments collected during the poster presentations.

\section{Results of the 2000 study}

Sixty-six students created 313 notes during the three-day course, and an additional 98 notes before the submission deadline of the final reports. The notes were visited 8,722 times during the course, with an additional 5,207 visits during the final report-making period. The notes were linked 106 times by $39 \mathrm{mem}$ bers. Among those links, 51 had comments on both ways, while 41 had one-directional comments only. The notes were actively used overall, possibly because the course-activities, such as presenting to the whole class, required such use. The notes were actively 
used even after the course, suggesting that the students took advantage of being able to revisit them while working on their final reports.

The quality of the final reports and the log data of ReCoNote use are currently being analyzed to examine what kinds of activities were related in what ways to the better performance obtained in this kind of collaborative class. TABLE 3 shows some preliminary results regarding when the links were made among the notes according to the phase (which day of the course) and whether they were links between a student's own notes, between one student's note to another's, or between/among others' notes.

TABLE 3 Number of links made -2000 class

\begin{tabular}{l|cccc}
\hline & Day & Day & Day3 & Total \\
\hline One's own notes & 0 & 6 & 5 & 11 \\
Own with other's notes & 0 & 33 & 17 & 50 \\
Among others' notes & 0 & 14 & 19 & 33 \\
Not clear & 1 & 7 & 4 & 12 \\
\hline Total & 1 & 60 & 45 & 106
\end{tabular}

There was a slight increase in the number of links made among others' notes, indicating a move from seeing some coherent structure among students' own notes to constructing some new structure by relating to notes not directly belonging to their own work. This is similar to the observation made in the abovereported class.

\section{TECHNOLOGICAL SUPPORT FOR BUILDING THE COMMUNITY OF CONSTRUCTIVE INTERACTION}

\section{Interactive Query Raiser: The system}

Through using ReCoNote, we gradually came to realize that students need time to become accustomed to the idea of knowledge sharing, to the value of co-construction of knowledge. In order to cultivate the practice of such intellectual collaboration, particularly for the beginners, a bulletin board that could be annotated was developed and used to list the lecture notes of the teachers (Nakayama \& Miyake, 2000). The notes were cut into short but meaningful lines for ease of reading and commenting. Lines of the texts were numbered, and by clicking the number, a window opened for writing questions, answers, and comments. The line with such a comment is shown accompanied

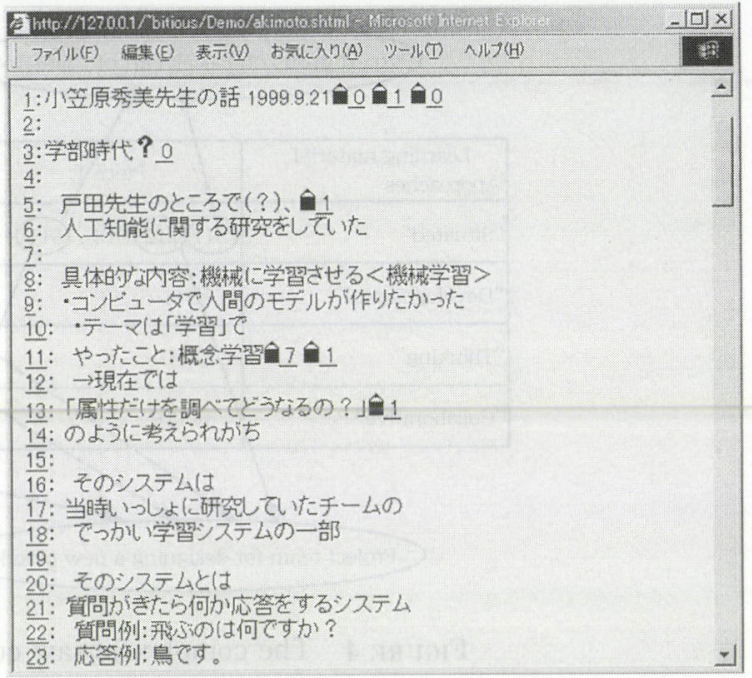

Figure 5 Interactive Query Raiser

by a small mark next to it, where the number of the marks corresponds to the number of comments the line received (FIGURE 5). The comments can in turn be commented on (we call these "responses"), and the small number next to the comment mark denotes how many "responses" each comment has. Thus in FIGURE 5, line 11 (eighth from the top) has 2 comments (shown by the pencil marks next to the text), and the first comment has 7 responses wlile the second one has only one. These questions/comments/answers and responses are all reachable by clicking on the marks.

\section{The course activities}

The 1999 Introductory Cognitive Science Course

In 1999, Interactive Query Raiser was used and tested in a course in which the faculty members introduced their own work in cognitive science to freshmen. They took turns giving two lectures (ninety minutes each per week for two weeks), and talked to the class about how they had come to do the kind of research they do now. After each lecture, the lecture notes prepared by the speakers were given to us, and we reformatted them to fit the system. Sometimes an assigned teaching assistant provided the notes. In two of the classes where the speaker left some time after the lecture, the class was moved to the computer-equipped room so that the students had some chance to use the system as a class. 


\section{Results of the 1999 study}

In total, 100 students used this system on 24 original texts provided by 7 teachers. They created $261 \mathrm{com}$ ments, with 193 responses. Simple count of the log reveals that the texts were visited 5,326 times while there were 5,367 visits to the comments.

The peaks of use corresponded to the days where the class could move to the computer room to use the system, indicating that the system was most heavily used when there was clear course guidance. By dividing the entire course with these land-mark days, we could see whether this mass creation contributed anything to the social sharing of commenting activities.

FIGURE 6 shows the number of comments and responses created in each period. The pattern shown here indicates that as the comments accumulated on the system, the number of the created comments and responses also grew. In fact, the fourth period is longer in time, thus this pattern mainly shows that the system gets used rather constantly, which we take as a sign that the habit of commenting and questioning spread throughout the course.

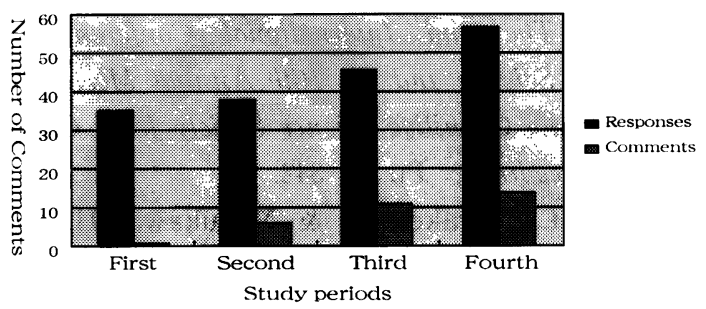

Figure 6 Number of comments and responses by period, divided by the peak days

Encouraged by these results, we are currently developing and testing a two-year course plan in our department. Students are first exposed to this kind of introductory use of collaborative technology and then gradually guided through technologically supported complex jigsaw classrooms so that they can develop from simpler to more complex knowledge construction skills on their own.

\section{CONCLUSION}

In our empirical studies of collaborative learning design, college students showed high flexibility in learning and creating both their knowledge in cognitive science and new ways to use their technological environments. Gradually they come to show respect to the community norm of constructive interaction, when the course work is carefully designed and practiced. It is also becoming clear, we feel, that a carefully structured class does have the potential for freeing up the students to start their own knowledge construction, relying on the structure itself as a scaffold and as the objective for learning at the same time. The underlying principles for such design are just emerging, and require more careful analyses of the processes of the students' learning. Many research findings in cognitive studies offer hints in doing our kind of practical research. Making such knowledge more widely known may be one of the next steps we have to take to strengthen the field of technological support studies in education.

We are currently developing similar course curricula to investigate how broad an area this kind of complex jigsaw structure can cover. Modern science requires collaborative teamwork, yielding more multidisciplinary results. Students not only in cognitive science but also in many other disciplines will soon need to start learning to cover more diverse topics. More research into collaborative learning in structurally collaborative and thus interdisciplinary and more complex research fields would certainly contribute to making this learning situation less difficult.

\section{Acknowledgements}

This is a partial report of a joint research project. For preparation of this paper, I particularly thank Hiroyuki Masukawa, Takahiro Nakayama, Hajime Shirouzu, Katsutoshi Yuasa, and Kayo Uetani. Support for this research came from Core Research for Evolutional Science and Technology 2000 of the Japan Science and Technology Corporation, High-Tech Research Center of the the Ministry of Education, and Grant-in-Aid for Scientific Research (B) (2) , 12480091.

\section{REFERENCES}

Aronson, E., \& Patnoe, S. 1997 The jigsaw classroom:

Building cooperation in the classroom. New York: Longman. 
Bereiter, C., \& Scardamalia, M. 1993 Surpassing ourselves: An inquiry into the nature and implications of expertise. Chicago: Open Court.

Bransford, J. D., Brown, A. L., \& Cocking, R. R. (Eds.) 2000 How people learn: Brain, mind, experience, and school. Expanded Ed. Washington, D.C.: National Academy Press.

Brown, A. 1997 Transforming schools into communities of thinking and learning about serious matters, American Psychologist, 52, 399-413.

Brown, J.S., Collins, A., \& Duguid, P. 1989 Situated cognition and the culture of learning. Educational Researcher, 18, 32-42.

Chi, M. T. H. 2000 Self-explaining: The dual processes of generating inference and repairing mental models. In R. Glaser (Ed.), Advances in instructional psychology: Educational design and cognitive science, Vol. 5. Mahwah, NJ: Erlbaum. Pp.161-238.

Cognition and Technology Group at Vanderbilt, The, 1997 The Jasper Project. Mahwah, NJ: Erlbaum.

Communications of the ACM 1993 Special issue on Learner-centered design, 36(5).

Fishman, B.J. \& O'Connor-Divelbiss, S. F. (Eds.) 2000 International Conference of the Learning Sciences 2000. Mahwah, NJ: Erlbaum.

Lave, J. 1988 Cognition in practice: Mind, mathematics, and culture in everyday life. Cambridge, MA: Cambridge University Press.

Linn, M.C. \& Hsi, S. 2000 Computers, teachers, peers: Science learning partners, Mahwah, NJ: Erlbaum.

Masukawa, H. 1999 Effects of the mutual links of a collaborative learning support system ReCoNote (Reflective Collaboration Note). Japanese Journal of Educational Technology, 23, 89-98. [in Japanese]

Miyake, N. 1986 Constructive interaction and the iterative process of understanding. Cognitive Sci- ence, 10(2), 151-177.

Miyake, N., in collaboration with the P.I.A. Group 1994 Personal knowledge: Its externalization, manipulation and sharing for scientific creative activities. International Symposium on Intellectual Facilitation of Creative Activities Proceedings. Pp. 14-19.

Miyake, N. 1996 Conditions for constructive interaction. Cognitive Studies: Bulletin of the Japanese Cognitive Science Society, 3(4), 26-27.

Miyake, N, \&, Masukawa, H. 2000 Relation-making to sense-making: Supporting college students' constructive understanding with an enriched collaborative note-sharing system. In Fishman, B.J., \& O'Connor-Divelbiss, S. F. (Eds.) International Conference of the Learning Sciences 2000. Mahwah, NJ: Erlbaum. Pp.41-47.

Nakayama, T., \& Miyake, N. 2000 A proposal of query-raising support by sharing questions and comments. Proceedings of the 17th Annual Meeting of the Japanese Cognitive Science Society. Pp.172-173. [in Japanese]

Shirouzu, H., Miyake, N., \& Masukawa, H. 1999 Roles of cognitive externalization for joint problem solving. The 2nd International Conference on Cognitive Science and the 16th Annual Meeting of the Japanese Cognitive Science Society Joint Conference Proceedings. Pp.337-342.

Shirouzu, H., Miyake, N., \& Masukawa, H. 2001 Cognitively active externalization for situated reflection. Submitted for review.

Williams, J., Hollan, J., \& Stevens, A. 1990 Human reasoning about a simple physical system. In D. Gentner \& A. Stevens (Eds.), Mental models. Mahwah, NJ: Erlbaum. Pp.131-153. 